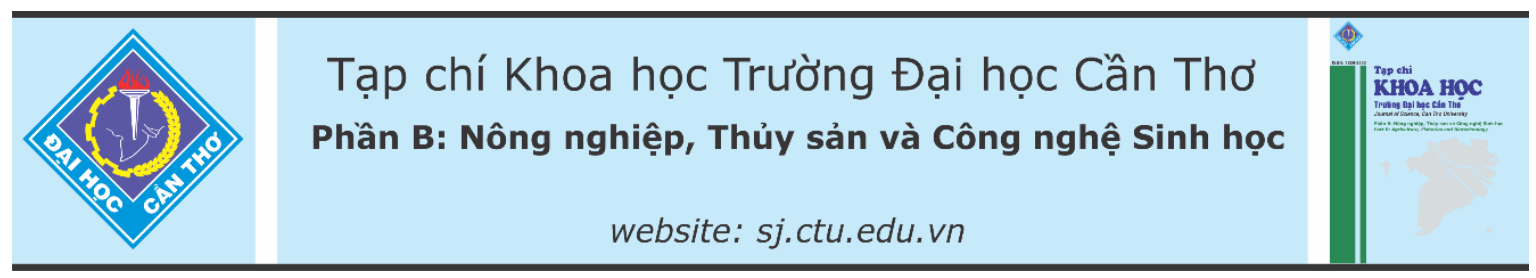

DOI:10.22144/ctu.jvn.2021.091

\title{
NGHIÊN CỨU THANH HẠT ĂN LIỀn BỔ SUNG HẠT CHANH DÂY
}

\author{
Hoàng Quang Bình ${ }^{1,2}$, Đặng Thành Duy ${ }^{1}$ và Lê Trung Thiên ${ }^{1,2^{*}}$ \\ ${ }^{1}$ Khoa Công nghệ thưc phẩm, Truờng Đại học Nông Lâm TP.HCM \\ ${ }^{2}$ Công ty trách nhiệm hũu hạn Lê Trung Thiên \\ *Nguoòi chịu trách nhiệm về bài viết: Lê Trung Thiên (email: le.trungthien@hcmuaf.edu.vn)
}

\section{Thông tin chung:}

Ngày nhận bài: $15 / 12 / 2020$

Ngày nhận bài sửa: 25/01/2021

Ngày duyệt đăng: 25/06/2021

\section{Title:}

Research of instant nut bars supplemented with passion fruit seed

\section{Tù khóa:}

Bao bì, hat chanh dây, polyphenol, thanh hat

\section{Keywords:}

Nut bar, packaging, passion fruit seeds, polyphenol

\begin{abstract}
Passion fruit seeds contain many compounds good for health such as antioxidant compounds, fiber, and essential fats. However, these seeds are currently only known as a by-product of passion fruit processing. This study was conducted to evaluate the applicability of passion fruit seeds in the processing of instant nut bars. Research results showed that passion fruit seeds accounted for $26.7 \%$ of total fruit weight, but $52.82 \%$ of total fruit polyphenols. The porosity of passion fruit seeds was improved when the seeds were treated with $3 \% \mathrm{NaHCO}_{3}$ solution for 16 hours; then dried at $60^{\circ} \mathrm{C}$ to 9-10\% moisture, then roasted. The instant nut bar based on recipe 2 containing passion fruit seed (15\%), soybean seed, cashew nut, sesame seed, sunflower seed, brown rice, peanut, honey, and glucose syrup gave the product had a good sensory. Nutritional facts of this product, in $100 \mathrm{~g}$, include carbohydrate 49.2 $\mathrm{g}$, fat $25.3 \mathrm{~g}$, protein $17.2 \mathrm{~g}$, and $493 \mathrm{kcal}$. Besides, this product reached total phenolic content $367 \mathrm{mg}$ GAE/100 $\mathrm{g}$ dm and antioxidant capacity DPPH $561.64 \mathrm{AAE} \mathrm{g} / 100 \mathrm{~g}$ dm. After 30 days of storage at room temperature, the samples were packed in a polyamide bag and an aluminum-coated bag with a moisture content of 7.42-6.16\%, water activity of 0.53-0.47, and peroxide content of 1.32 and $1.90 \mathrm{meq} / \mathrm{kg}$. Products packed in aluminum bags had lower peroxide content than those in polyamide bags.
\end{abstract}

\section{TÓM TÁT}

Hạt chanh dây có chưa hợp chất kháng oxy hóa, chất xo: chất béo thiết yếu tốt cho sức khỏe. Tuy nhiên, hạt chanh dây hiện nay chỉ mới được biết đến là nguồn phu phẩm của quá trình chế biến nuoóc chanh dây. Nghiên cứu được thực hiện nhằm đánh giá khả năng ứng dụng hạt chanh dây trong chế biến thanh hạt ăn liền. Kết quả nghiên cứu cho thấy hạt chanh dây chiếm $26,7 \%$ tổng khối luợng trái, nhung chiếm $52,82 \%$ khối luợng polyphenol toàn trái. Độ giòn xốp của hạt chanh dây được cải thiện khi hạt đươc xư lý với dung dịch $\mathrm{NaHCO}_{3} 3 \%$ trong 16 giò; hạt sau đó đươc sấy ơ $60^{\circ} \mathrm{C}$ đến ẩm 9-10\%, rang hạt. Thanh hat ăn liền chế biến theo công thức 2 có thành phần hạt chanh dây chiếm 15\%, hạt đậu nành, hạt điều, hạt mè, hạt hướng duoong, hạt gạo lức, hạt đậu phộng, mật ong, glucose syrup nhận được nhiều sư yeu thich về cảm quan của các cảm quan viên. Sản phẩm chế biến tù̀ công thức này, trong $100 \mathrm{~g}$ có carbohydrate 49,2 g, chất béo 25,3 g, hàm luợng protein 17,2 g, năng luợng $493 \mathrm{kcal} / 100 \mathrm{~g}$, hàm luợng polyphenol $367 \mathrm{mg}$ GAE/100 $\mathrm{g}$ vật chất khô, hoạt tỉnh kháng oxy hóa DPPH 561,64 AAE g/ $100 \mathrm{~g}$ vật chất khô. Sau 30 ngày bảo quản ở nhiệt độ phòng, mẫu sản phẩm được bao gói trong bao polyamide và bao tráng nhôm có độ ẩm 7,42-6,16\%, hoạt độ nước 0,53-0,47 và hàm lương peroxide 1,32 và 1,90 (meq $/ \mathrm{kg})$. Sản phẩm bảo quản bằng bao tráng nhôm có hàm luợng peroxide it hơn so với bảo quản bằng bao polyamide. 


\section{1. ĐẶT VẤN ĐỀ}

Sự phát triển nhanh chóng của nền kinh tế giúp nâng cao nhận thức về sức khỏe của con người. Một chế độ ăn uống cân bằng là phương pháp hiệu quả để phòng ngừa, các nguy cơ xuất hiện các bệnh mãn tính không lây như bệnh tiểu đường, suy dinh dưỡng, béo phì và bệnh. Việc liên tục nghiên cứu phát triển các các sản phẩm mới có giá trị dinh dưỡng, có lợi cho sức khỏe người tiêu dùng là thử thách cho ngành công nghiệp chế biến thực phẩm. Thanh dinh dưỡng là sản phẩm kết hợp các loại hạt với nhau, cung cấp nhiều năng lượng, chất xơ, vitamins, chất khoáng (Ahmad et al., 2017; Mendes et al., 2013; Palazzolo, 2003). Sản phẩm này đã xuất hiện phổ biến tại thị trường châu Âu, Mỹ và bắt đầu du nhập vào thị trường Việt Nam trong những năm gần đây. Phát triển sản phẩm thanh dinh dưỡng phù hợp với thị hiếu người tiêu dùng Việt là một bước quan trọng trong việc phát triển dòng sản phẩm này ở thị trường trong nước. Bên cạnh đó, các sản phẩm nhập ngoại được chế biến chủ yếu từ các loại hạt không có sẵn tại Việt Nam, làm giá thành sản phẩm cao, người tiêu dùng khó tiếp cận sử dụng.

Hạt chiếm 8-12\% tổng khối lượng toàn trái chanh dây (Reis et al., 2018). Hạt giàu chất béo, protein, chất xơ và chất khoáng (Reis et al., 2018., Chau and Huang., 2004). Đặc biệt trong hạt chanh dây chứa $85 \%$ chất béo thiết yếu có vai trò quan trọng trong việc ngăn ngừa các bệnh tim mạch như xơ vữa động mạch, huyết áp cao, động mạch vành (Ramaiya et al., 2019; Piombo et al., 2006). Trong hạt còn chứa các nhóm chất có hoạt tính sinh học gồm tocopherols, hợp chất phenolic (Nguyen et al., 2020; Piombo et al., 2006). Chế biến các sản phẩm có vận dụng hạt trong chanh dây vẫn chưa được đề cập nhiều trong các công trình nghiên cứu trong và ngoài nước; do đó, tiềm năng về kinh tế của loại hạt này vẫn chưa được khai thác tối đa. Mục tiêu của nghiên cứu này là tạo ra thanh hạt có bổ sung hạt chanh dây, sản phẩm vừa chứa nhiều hợp chất polyphenol vừa có chất lượng cảm quan tốt; đồng thời sự biến một số thông số hóa lý của sản phẩm trong quá trình bảo quản cũng được ghi nhận.

\section{PHƯƠNG PHÁP NGHIÊN CÚU}

\subsection{Nguyên liệu, hóa chất và thiết bị}

Nguyên liệu: Chanh dây được mua tại chợ đầu mối Nông Sản Thủ Đức, TP.HCM. Quả chanh dây được lựa chọn là trái tươi có khối lượng $70-75 \mathrm{~g}$, không bị dập, thối; dịch quả có hàm lượng tổng chất rắn hòa tan là $15,2 \pm 1,57^{\circ} \mathrm{Bx}$, acid tổng số là 2,99 $\pm 0,60 \%$. Chanh dây sau khi thu mua, được rửa sạch và tách riêng phần dịch quả và hạt. Hạt được bảo quản ở $-18^{\circ} \mathrm{C}$. Các loại hạt khác gồm hạt mè, hạt điều, hạt đậu nành, đậu phộng, gạo lức, hạt hướng dương và mật ong được thu mua tại siêu thị Coop Xtra Linh Trung, Thủ Đức, TP.HCM.

Hóa chất: Acetic acid; KI; $\mathrm{Na}_{2} \mathrm{~S}_{2} \mathrm{O}_{3} 99 \%$; acetone; $\mathrm{Na}_{2} \mathrm{CO}_{3}$ (Xilong, Trung Quốc); hexane, cồn tuyệt đối; chlorofrom (Chemsol, Việt Nam), Folin-Ciocalteu 99,5\%, DPPH (EMD Millipore Đức),

Thiết bị: Cân phân tích 4 số lẽ, tủ sấy khí nóng National C - 30N (Nhật Bản), máy đo màu Konica Minolta Chroma Meter CR - 400 (Nhật Bản), cân ẩm hồng ngoại MX - 50 - AND (Nhật Bản), máy đo quang phổ UV Vis V730 Jasco (Nhật Bản).

\subsection{Bố trí thí nghiệm}

\subsection{1. Đánh giá sự phân bố polyphenol trên quả chanh dây}

Quả chanh dây sau khi thu mua được vận chuyển về phòng thí nghiệm. Các bộ phận của trái bao gồm dịch quả, vỏ và hạt chanh dây được phân tích khối lượng, hàm lượng phenolic tổng.

\subsubsection{Anh hương của phương pháp tiền xử lý đến chất lương hạt chanh dây}

Thí nghiệm 1 yếu tố là phương pháp tiền xử lý hạt. Hạt chanh dây sau khi rã đông, rửa sạch bằng nước được tiền xử lý theo 3 phương pháp khác nhau. Phương pháp 1: luộc nguyên liệu trong nước sôi ở $100^{\circ} \mathrm{C}$ trong 20 phút, tî lệ giữa hạt với nước là 1:5. Sau đó, hạt được vớt ra để ráo rồi đem đi sấy bằng máy sấy khí nóng đối lưu ở nhiệt độ $60^{\circ} \mathrm{C}$ cho đến khi ẩm độ của hạt đạt 9-10\%. Phương pháp 2: hạt chanh dây được ngâm trong dung dịch $\mathrm{NaHCO}_{3} 3 \%$ trong 16 giờ ở nhiệt độ phòng. Sau đó, hạt được rửa với nước và để ráo rồi đem đi sấy ở nhiệt độ $60^{\circ} \mathrm{C}$ cho đến khi ẩm độ của hạt đạt $9-10 \%$. Phương pháp 3: Hạt đem đi sấy ở nhiệt độ $60^{\circ} \mathrm{C}$ cho đến khi ẩm độ của hạt đạt 9-10\% (mẫu đối chứng). Hạt chanh dây thu nhận từ mỗi phương pháp được rang ở nhiệt độ $120-130^{\circ} \mathrm{C}$ trong 5-7 phút. Mẫu sau đó được đựng trong bao polyproylene tráng nhôm và bảo quản ở nhiệt độ phòng $29-31^{\circ} \mathrm{C}$. Hạt chanh dây sau mỗi công đoạn gồm hạt nguyên liệu tươi, tiền xử lý, sau sấy và sau rang được đánh giá hàm lượng polyphenol tổng. Hạt sau rang được đánh giá cảm quan thị hiếu.

\subsubsection{Anh hương của công thức phối trộn nguyên liệu đến chất lương sản phẩm}

Thí nghiệm 1 yếu tố là công thức phối trộn nguyên liệu được trình bày trong Bảng 1 . Quy trình 
chuẩn bị hạt chanh dây được thực hiện tương tự như muc 2.3.2; trong đó phương pháp tiền xử lý hạt là kết quả thí nghiệm mục 2.3.2. Hạt chanh dây, hạt điều, hạt mè, gạo lức, đậu nành, hạt hướng dương, đậu phộng, hỗn hợp glucose syrup và mật ong được trộn đều ở $100^{\circ} \mathrm{C}$ trong 2 phút. Sau đó tất cả các nguyên liệu được cho vào khuôn có kích thước $3 \times 8 \times 2 \mathrm{~cm}$ và được để nguội tại nhiệt độ phòng trong 1 giờ. Mẫu sau đó được phân tích hàm lượng polyphenol tổng, hoạt tính chống oxy hóa (DPPH) và cảm quan thị hiếu.

\subsubsection{Anh hưởng loại bao bi bao gói đến biến đổi chất lương sản phẩm}

Thí nghiệm 1 yếu tố là loại bao bì bao gói gồm 2 loại polyarmide và polypropylene tráng nhôm. Quy trình chuẩn bị mẫu được thực hiện tương tự mục 2.3.2, trong đó công thức phối trộn hạt chanh dây là kết quả thí nghiệm mục 2.3.2. Trong quá trình bảo quản tại nhiệt độ phòng $29-31^{\circ} \mathrm{C}$ tại các thời điểm $0,7,14,21$ và 30 ngày mẫu được xác định ẩm độ, hoạt độ và chỉ số peroxide. Đơn vị thí nghiệm $150 \mathrm{~g}$.

\section{Bảng 1. Công thức phối trộn nguyên liệu}

\begin{tabular}{lrrrr}
\hline Thành phần nguyên & \multicolumn{4}{c}{ Công thức chế biến } \\
\cline { 2 - 5 } liệu & $\mathbf{1}$ & $\mathbf{2}$ & $\mathbf{3}$ & $\mathbf{4}$ \\
\hline Hạt chanh dây & 0 & 15 & 20 & 40 \\
Hạt đậu nành & 20 & 14 & 13 & 8 \\
Hạt điều & 15 & 8 & 8 & 8 \\
Hạt mè trắng & 7 & 5 & 5 & 5 \\
Hạt hướng dương & 12 & 12 & 10 & 5 \\
Hạt gạo lức & 11 & 11 & 10 & 5 \\
Đậu phộng & 11 & 11 & 10 & 5 \\
Mật ong & 11 & 11 & 11 & 11 \\
Glucose Syrup & 13 & 13 & 13 & 13 \\
\hline Tổng cộng & \multicolumn{4}{c}{} \\
\hline
\end{tabular}

\subsection{Các phương pháp phân tích}

Hàm luợng polyphenol tổng: Phương pháp phân tích được tham chiếu theo Singleton et al. (1965) và có hiệu chỉnh. Hút $0,5 \mathrm{~mL}$ dịch mẫu cho vào ống nghiệm, thêm $2,5 \mathrm{~mL}$ Folin-Ciocalteu $10 \%$ lắc đều và để yên trong tối khoảng 5 phút. Sau đó cho thêm $2 \mathrm{~mL} \mathrm{Na} \mathrm{CO}_{3} 7,5 \%$ vào ống nghiệm và lắc đều, để tối trong 60 phút rồi đem đi đo độ hấp thụ quang phổ ở bước sóng $765 \mathrm{~nm}$. Dựa vào phương trình đường chuẩn gallic acid, hàm lượng polyphenol tổng được thể hiện theo mg GAE/100 g mẫu.

Hoạt tính chống oxy hóa: Phương pháp phân tích được tham chiếu theo Thaipong et al. (2006). Hút $0,2 \mathrm{~mL}$ mẫu đã được pha loãng vào ống nghiệm, sau đó cho $4 \mathrm{~mL}$ dung dịch $\mathrm{DPPH} 0.1 \mathrm{mM}$ vào lắc đểu, để yên cho phản ứng trong bóng tối 30 phút. Sau đó độ hấp thụ quang phổ ở bước sóng $517 \mathrm{~nm}$. Dựa vào phương trình đường chuẩn ascorbic acid hoạt tính chống oxy hóa được thể hiện theo mg AAE/100 g mẫu.

Chi số peroxide được xác định theo tiêu chuẩn TCVN 6121:2010 (ISO 3960:2007) (Bộ Khoa học và Công nghệ, 2010). Cân $3 \mathrm{~g}$ chất béo cho vào bình erlen $250 \mathrm{~mL}$. Thêm $10 \mathrm{~mL}$ chloroform, $15 \mathrm{~mL}$ acetic acid, $1 \mathrm{~mL}$ dung dịch KI bão hòa. Mẫu được lắc đều và phản ứng 5 phút trong điều kiện chắn sáng. Sau đó cho $75 \mathrm{~mL}$ nước cất, 5 giọt dung dịch hồ tinh bột vào trong mẫu và lắc đều. Mẫu được chuẩn độ với $\mathrm{Na}_{2} \mathrm{~S}_{2} \mathrm{O}_{3} 0.002 \mathrm{~N}$ cho đến khi mất màu. Mẫu trắng làm tương tự nhưng thay mẫu bằng nước cất. Trị số peroxide tính bằng đương lượng mili oxy hoạt tính trên $\mathrm{kg}$ mẫu thử, được tính theo công thức:

$$
\mathrm{V}=\frac{(\mathrm{V} 1-\mathrm{V} 2) \times \mathrm{N}}{\mathrm{M}} \times 1000
$$

Trong đó: PV chỉ số peroxide, meq/kg. V1 số $\mathrm{mL} \mathrm{Na} \mathrm{S}_{2} \mathrm{O}_{3} \quad 0,002 \mathrm{~N}$ dùng để định phân mẫu thí nghiệm. V2 số $\mathrm{mL} \mathrm{Na}_{2} \mathrm{~S}_{2} \mathrm{O}_{3} \quad 0,002 \mathrm{~N}$ dùng để định phân mẫu kiểm chứng (mẫu trắng). $\mathrm{M}$ khối lượng mẫu thí nghiệm $(\mathrm{g})$. N Nồng độ đương lượng gam $\mathrm{Na}_{2} \mathrm{~S}_{2} \mathrm{O}_{3}$ sử dụng.

Phương pháp cảm quan: mẫu được cảm quan bằng phép thử cho điểm thị hiếu theo thang điểm 9 ; trong đó 1 : cực kì không thích và 7 : cực kì thích. Mẫu thí nghiệm được đánh giả bởi 30 cảm quan viên sinh viên khoa Công nghệ thực phẩm, Trường Đại học Nông Lâm TP.HCM. Các cảm quan viên không sử dụng bất kì thực phẩm nào trước 30 phút thử mẫu. Mỗi cảm quan viên được nhận $10 \mathrm{~g}$ mẫu, mẫu đựng trong đĩa trắng, mỗi mẫu được mã hóa bằng số 3 chữ số. Sau mỗi lần thử mẫu, người đánh giá sử dụng nước lọc để thanh vị.

\subsection{Xử lý số liệu}

Tất cả các thí nghiệm được lặp lại 3 lần, các kết quả được thể hiện dưới dạng trung bình \pm độ lệch chuẩn. Các số liệu thu thập được tính toán, vẽ đồ thị bằng Excel 2013.Các phân tích phương sai (Anova) được thực hiện, sự khác biệt về mặt thống kê của các kết quả được xử lý bằng phần mềm JMP 13.0 tại $\mathrm{p}<$ 0,05 .

\section{KÊT QUẢ VÀ THẢO LUẬN}

\section{1. Đánh giá sự phân bố polyphenol trên quả chanh dây}

Vỏ quả chiếm tỷ lệ cao nhất $(59,43 \%)$ trên tổng khối lượng quả, tiếp đến là thành phần dịch quả $(26,47 \%)$ và hạt $(14,10 \%)$. Kết quả nghiên cứu của 
Reis et al. (2018) xác định tỉ lệ giữa các thành phần vỏ quả, dịch quả và hạt lần lượt là: $62,11 \% ; 25,23 \%$; $12,66 \%$. Các kết quả này cho thấy thành phần được xem là không ăn được (vỏ, hạt) chiếm tỉ lệ lớn (hơn $70 \%$ ) trong khối lượng quả chanh dây. Hình 1 cho thấy hàm lượng polyphenol tổng ở hạt cao nhất,

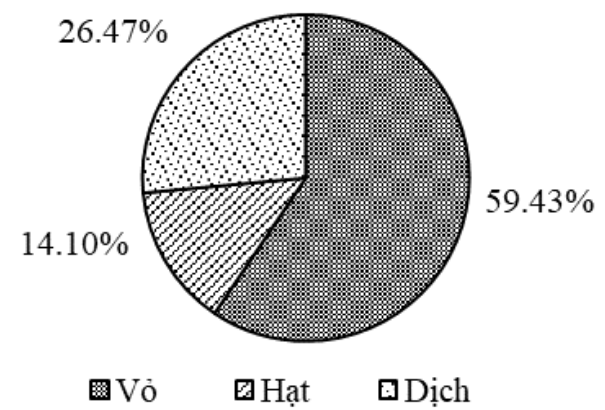

A chiếm $52,82 \%$ trên tổng khối lượng quả, tiếp theo là phần vỏ $(42,22 \%)$ và dịch quả $(4,95 \%)$. Nghiên cứu của Nguyen et al. (2019) cũng đã ghi nhận hàm lượng phenolic acid hòa tan và liên kết ở hạt chanh dây lần lượt là $0,44 \mathrm{~g} \mathrm{GAE} / 100 \mathrm{~g} ; 1,47$ g GAE/100 $\mathrm{g}$ cao hơn so với dịch quả chanh dây.

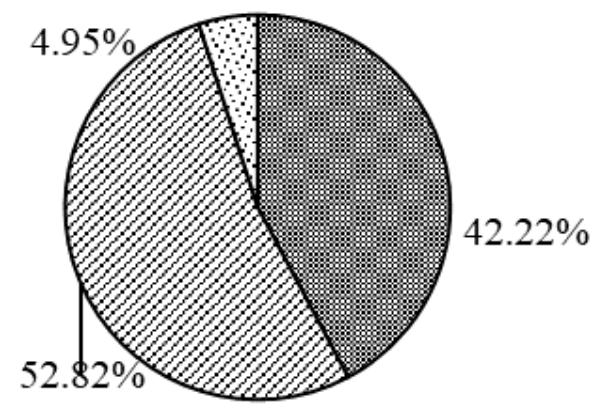

B

Hình 1. (A) Khối lượng từng bộ phận trái chanh dây và (B) hàm lượng polyphenol tổng tính trên tổng khối lượng quả. $\mathrm{N}=10$

\section{2. Ảnh hưởng của phương pháp tiền xử lý đến chất lượng hạt chanh dây}

Mẫu ngâm $\mathrm{NaHCO}_{3}$ được các cảm quan viên đánh giá là có vị béo, mùi thơm đặc trưng $(5,67$ điểm) hơn so với hai mẫu còn lại (4,42-5,0 điểm). Độ giòn của hạt chanh dây ở nghiệm thức ngâm $\mathrm{NaHCO}_{3}$ tốt hơn được cảm viên yêu thích nhất $(5,42$ điểm), kế tiếp là nghiệm thức luộc $(4,75$ điểm) và mẫu không xử lý (4,25 điểm). Khi ngâm hạt trong dung dịch $\mathrm{NaHCO}_{3}, \mathrm{NaHCO}_{3}$ thẩm thấu vào lớp vỏ bao quanh nhân, phản ứng của gốc $\mathrm{HCO}_{3}{ }^{-}$khi có sự hiện diện của ion $\mathrm{H}^{+}$có trong nước sẽ sinh ra khí $\mathrm{CO}_{2}$ len lỏi ra khỏi lớp vỏ, làm xuất hiện các lỗ rỗng trong và ngoài vỏ hạt giúp hạt giòn xốp khi nhai. Ở phương pháp luộc, nhiệt độ cao phá vỡ cấu trúc tế bào, protopectin trong nguyên liệu bị chuyển thành pectin hòa tan làm mềm cấu trúc sản phẩm luộc cũng cải thiện được độ xốp của hạt chanh dây. Nhìn chung, hạt chanh dây được xử lý bằng phương pháp ngâm $\mathrm{NaHCO}_{3}$ có đặc điểm cảm quan được nhiều cảm quan viên yêu thích nhất cũng như giữ lại nhiều hàm lượng hợp chất polyphenol.

Bảng 1. Ảnh hưởng của phương pháp tiền xử lý đến chất lượng cảm quan hạt chanh dây thành phẩm

\begin{tabular}{clll}
\hline Phương pháp xử lý & Mùi vị & Độ giòn & Tổng thể \\
\hline 1 & $4,42^{\mathrm{b}} \pm 0,67$ & $4,75^{\mathrm{b}} \pm 0.62$ & $5,00^{\mathrm{a}} \pm 0,85$ \\
2 & $5,67^{\mathrm{a}} \pm 0,65$ & $5,42^{\mathrm{a}} \pm 0.79$ & $5,50^{\mathrm{a}} \pm 0,79$ \\
3 & $5,00^{\mathrm{b}} \pm 0,85$ & $4,25^{\mathrm{b}} \pm 0.75$ & $4,17^{\mathrm{b}} \pm 0,72$ \\
\hline
\end{tabular}

1: Chần hạt $100^{\circ} \mathrm{C} / 20$ phút, sấy khi nóng đối luu $60^{\circ} \mathrm{C}$ đến ẩm 9-10\%, rang hạt. 2: Ngâm hạt trong $\mathrm{NaHCO}_{3} 3 \% / 16$ giờ, rửa hạt, sấy khi nóng đối luu $60^{\circ} \mathrm{C}$ đến ẩm 9-10\%, rang hạt. 3: Sấy khi nóng đối luu $60^{\circ} \mathrm{C}$ đến ẩm 9-10\%, rang hạt. 1: Rất không thích, 7: Rất thích. Giá trị trung bình với các ký tư $(a, b, c)$ giống nhau trong cùng một cột là khác biệt không có ýnghĩa thống kê ( $p>0.05)$.

Sự khác nhau về hàm lượng polyphenol tổng của hạt chanh dây ở cả 3 mẫu qua từng công đoạn chế biến như tiền xử lý, sấy và rang không có ý nghĩa thống kê ở độ tin cậy $95 \%$. Phần trăm suy thoái hợp chất phenolic acid ở mỗi công đoạn chế biến là như nhau khoảng 5\%. Tỷ lệ polyphenol còn lại ở mẫu xử lý theo phương pháp 1,2 và 3 lần lượt là $79 \%$, $82,73 \%$ và $84,12 \%$. Dưới tác động của nhiệt độ cao của sấy, rang đã làm suy giảm hợp chất này có trong hạt chanh dây. 


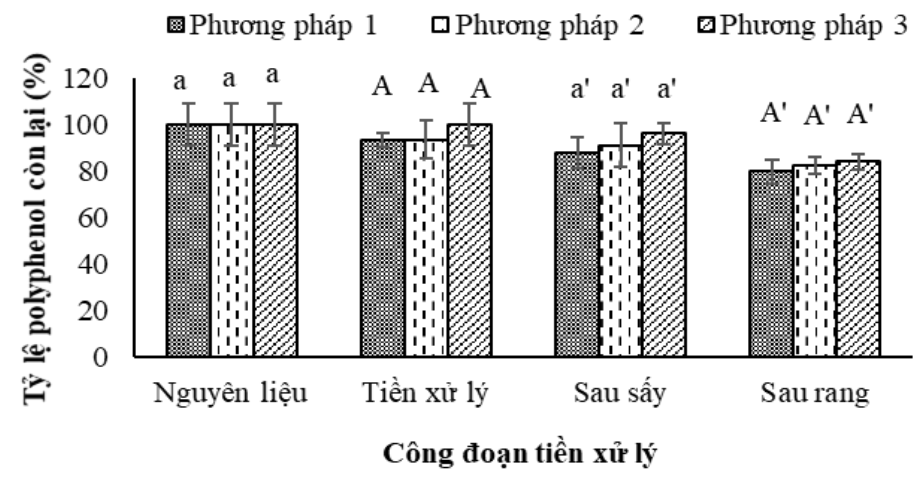

Hình 2. Tỷ lệ polyphenol còn lại sau mỗi công đoạn chế biến ở mỗi phương pháp tiền xử lý hạt chanh dây

1: Luộc hạt $100^{\circ} \mathrm{C} / 20$ phút, sấy khi nóng đối luu $60^{\circ} \mathrm{C}$ đến ẩm 9-10\%, rang hạt. 2: Ngâm hạt trong $\mathrm{NaHCO}_{3} 3 \% / 16$ giờ, rửa hạt, sấy khi nóng đối luu $60^{\circ} \mathrm{C}$ đến ẩm 9-10\%, rang hạt. 3: Sấy khí nóng đối luu $60^{\circ} \mathrm{C}$ đến ẩm 9-10\%, rang hạt. Giá trị trung bình với các ký tụ $(a, b, c)$ giống nhau trong cùng một công đoạn xủ lý là khác biệt không có ý nghĩa thống kê $(p>0.05)$.

3.3. Ảnh hưởng của công thức phối trộn nguyên liệu đến chất lượng sản phẩm

Sự yêu thích của các cảm quan viên đối cảm quan của sản phẩm là khác nhau ở các công thức chế biến (Bảng 2). Mẫu được chế biến theo công thức 2 có điểm số cảm quan cao nhất là 6,91 điểm; tiếp đến

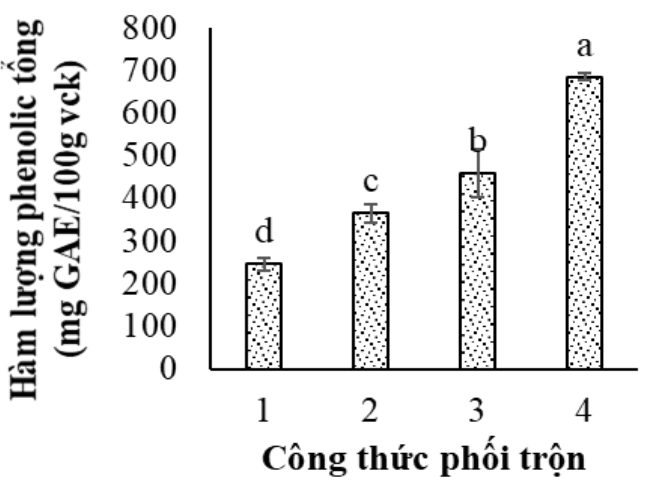

A

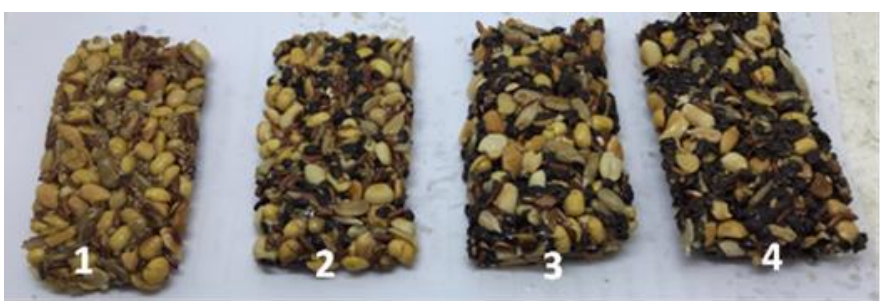

C

Hình 3. Ảnh hưởng của công thức chế biến đến (A) hàm lượng polyphenol tổng, (B) hoạt tính chống oxy hóa và $(C)$ vẻ bề ngoài của sản phẩm

Các công thức chế biến 1, 2, 3, 4 tuoong ứng với tỷ lệ hạt chanh dây có trong sản phẩm là 0\%, 15\%, 20\%, 40\%. Giá trị trung bình với các ký tụ $(a, b, c)$ giống nhau trong cùng một định dạng cột là khác biệt không có ý nghĩa thống kê $(p>0.05)$. 
Bảng 2. Ảnh hưởng của công thức phối trộn đến chất lượng cảm quan sản phẩm

\begin{tabular}{crrrr}
\hline \multirow{2}{*}{ Công thức } & \multicolumn{4}{c}{ Điểm cảm quan } \\
\cline { 2 - 5 } & Độ giòn & Mùi vị & Hương thơm & Tổng thể \\
\hline 1 & $4,80^{\mathrm{b}} \pm 0,72$ & $4,86^{\mathrm{b}} \pm 0,75$ & $4,92^{\mathrm{b}} \pm 0,49$ & $5,06^{\mathrm{a}} \pm 0,67$ \\
2 & $5,44^{\mathrm{a}} \pm 0,85$ & $5,70^{\mathrm{a}} \pm 0,49$ & $5,37^{\mathrm{a}} \pm 0,79$ & $5,37^{\mathrm{a}} \pm 0,79$ \\
3 & $4,47^{\mathrm{b}} \pm 0,96$ & $4,53^{\mathrm{b}} \pm 0,39$ & $4,34^{\mathrm{c}} \pm 0,66$ & $4,28^{\mathrm{b}} \pm 0,67$ \\
4 & $3,50^{\mathrm{c}} \pm 0,52$ & $3,63^{\mathrm{c}} \pm 0,49$ & $3,44^{\mathrm{d}} \pm 0,51$ & $3,56^{\mathrm{c}} \pm 0,67$ \\
\hline
\end{tabular}

Các công thức chế biến 1, 2, 3, 4 tương ứng với tỷ lệ hạt chanh dây có trong sản phẩm là 0\%, 15\%, 20\%, 40\%. Giá trị trung bình với các ký tụ $(a, b, c)$ giống nhau trong cùng một cột là khác biệt không có ý nghĩa thống kê (p>0.05). 1: Rất không yêu thích, 7: Rất thích

Hàm lượng polyphenol tổng và hoạt tính kháng oxi hóa ở các công thức phối trộn có sự khác biệt về ý nghĩa thống kê ở độ tin cậy $95 \%$. Mẫu không bổ sung hạt chanh dây có hàm lượng polyphenol tổng và hoạt tính kháng oxi hóa thấp nhất $(248,33 \mathrm{mg}$ $\mathrm{GAE} / 100 \mathrm{~g} ; 410,30 \mathrm{mg}$ AAE/100 g; giá trị tương ứng lần lượt). Cả hai giá trị này đều tăng dần theo chiều tăng tỉ lệ hạt chanh dây có trong sản phẩm và đạt giá trị cao nhất ở mẫu chế biến theo công thức 4 (hạt chanh dây chiến $40 \%$ ); hàm lượng polyphenol polyphenol tổng là $690,59 \mathrm{mg} \mathrm{GAE} / 100 \mathrm{~g}$ và hoạt tính kháng oxi hóa là 1075,68 mg AAE/100 g. Mầu được chế biến theo công thức 2 có hương vị cảm quan hài hòa, mới lạ, giòn xốp được cảm quan viên yêu thích nhất, đây được chọn là yếu tố cố định cho thí nghiệm tiếp theo.

\section{Bảng 3. Thành phần dinh dưỡng của thanh hạt} ăn liền

\begin{tabular}{cllr}
\hline STT & Chỉ tiêu* & Đơn vị & $\begin{array}{r}\text { Hàm } \\
\text { lượng** }\end{array}$ \\
\hline 1 & Carbohydrate & $\mathrm{g} / 100 \mathrm{~g}$ & 49,2 \\
2 & Chất béo & $\mathrm{g} / 100 \mathrm{~g}$ & 25.3 \\
3 & Protein & $\mathrm{g} / 100 \mathrm{~g}$ & 17,2 \\
4 & Năng lượng & $\mathrm{kcal} / 100 \mathrm{~g}$ & 493 \\
\hline
\end{tabular}

*: Mẫu được gưi phân tích tại Trung tâm Sắc Kí Hải Đăng **: Mẫu được chế biến theo công thức 2

Carbohydrate là thành phần chiếm tỷ lệ cao nhất $(49,2 \%)$, kế tiếp là chất béo $(25,3 \%)$ và protein $(17,2 \%)$ có trong thanh hạt được chế biến theo công thức 2. Các sản phẩm thanh hạt ăn liền nguồn gốc từ nước ngoài hiện có trên thị trường có hàm lượng protein $7,5-9,8 \%$, hàm lượng chất béo $12,3-22,4 \%$, hàm lượng carbohydrate là 55,6-60,8\%, tổng năng lượng 354-468 Kcal. Trong nghiên cứu trước đó của Ahmad et al. (2017), thanh hạt yến mạch ăn liền có hàm lượng protein là $12,51 \%$, hàm lượng chất béo $10,34 \%$, hàm lượng carbohydrate là $60,69 \%$, tổng năng lượng 421,88 Kcal; hàm lượng các hợp chất này trong hạt được chế biến theo nghiên cứu của Mendes et al. (2013) là 9,91\%, 14,55\%, 61,61\%, $416,99 \%$, tương ứng lần lượt. Như vậy, thanh hạt được chế biến trong nghiên cứu này có đặc điểm cảm quan phù hợp với người tiêu dùng Việt Nam, đồng thời vẫn duy trì được giá trị dinh dưỡng vốn có của dòng sản phẩm này.

\section{4. Ảnh hưởng loại bao bì bao gói đến biến đổi chất lượng sản phẩm}

Ngày đầu tiên của quá trình bảo quản mẫu có hàm lượng peroxide thấp nhất là bì $1,31 \mathrm{meq} / \mathrm{kg}$ (polyamide) và $1,32 \mathrm{meq} / \mathrm{kg}$ (bao bì tráng nhôm). Chỉ số này đạt nồng độ cao nhất sau 30 ngày bảo quản với nồng độ peroxide ghi nhận được là 1,90 $\mathrm{meq} / \mathrm{kg}$ ở bao bì polyamide và $1,48 \mathrm{meq} / \mathrm{kg}$ ở bao bì tráng nhôm. Sự gia tăng hàm lượng peorxide theo thời gian bảo quản cũng đã được ghi nhận trong các nghiên cứu trước đó về thanh ngũ cốc bổ sung hạt đậu nành (Yadav et al., 2016), thanh hạt diêm mạch sô cô la (Padmashree et al., 2018). Bao bì polyamide có chỉ số PV cao hơn so với bao bì tráng nhôm ở tất cả các thời điểm quan sát. Điều này có thể được giải thích vì thuộc tính của mỗi loại bao bì khác nhau; bao bì tráng nhôm có bản chất là bao bì chắn sáng có cấu tạo gồm nhiều lớp, có khả năng hạn chế ánh sáng, thấm khí từ môi trường bảo quản do đó hạn chế sự tương tác của oxy, ánh sáng với chất béo không bão hòa có trong thanh dinh dưỡng; giúp hạn chế sự phát triển quá trình oxy hóa chất béo. Sau 30 ngày bảo quản ở nhiệt độ phòng, hàm peroxide ở tất cả các mẫu vẫn nằm trong giới hạn cho phép theo quy định TCVN 10127:2013 (Bộ Khoa học và Công nghệ, 2013) là nhỏ hơn 10 meq/kg.

Mẫu bảo quản bằng bao bì tráng nhôm và bao bì polyamide có độ ẩm lần lượt là $7,42 \%$ và $7,16 \%$ trong ngày đầu tiên của quá trình bảo quản. Đến ngày 30 , độ ẩm của mẫu ở hai vật liệu này tương ứng lần lượt là là $6,16 \%$ và $6,28 \%$. Hoạt độ nước của mẫu thấp nhất sau 30 ngày bảo quản 0,47 (bao bì polyamide) và 0,46 (bao bì tráng nhôm); trong suốt quá trình bảo quản, mẫu luôn có hoạt độ nước nhó hơn 0,6 ; giá trị an toàn giúp hạn chế sự phát triển của vi sinh vật. Như vậy, nhìn chung theo thời gian bảo quản, hàm lượng peroxide tăng dần; trong 
khi đó ẩm độ và hoạt độ nước giảm dần. Trong quá trình bảo quản mẫu vẫn giữ được mùi thơm của các loại hạt, giòn xốp và không xuất hiện mùi ôi. Bảo

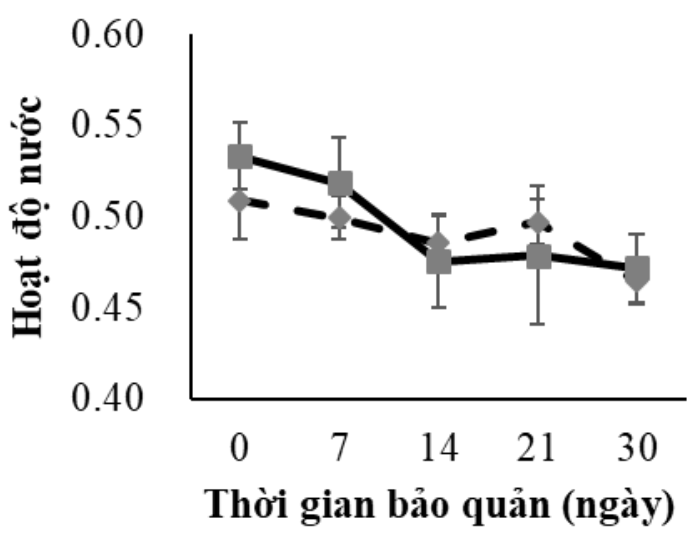

A

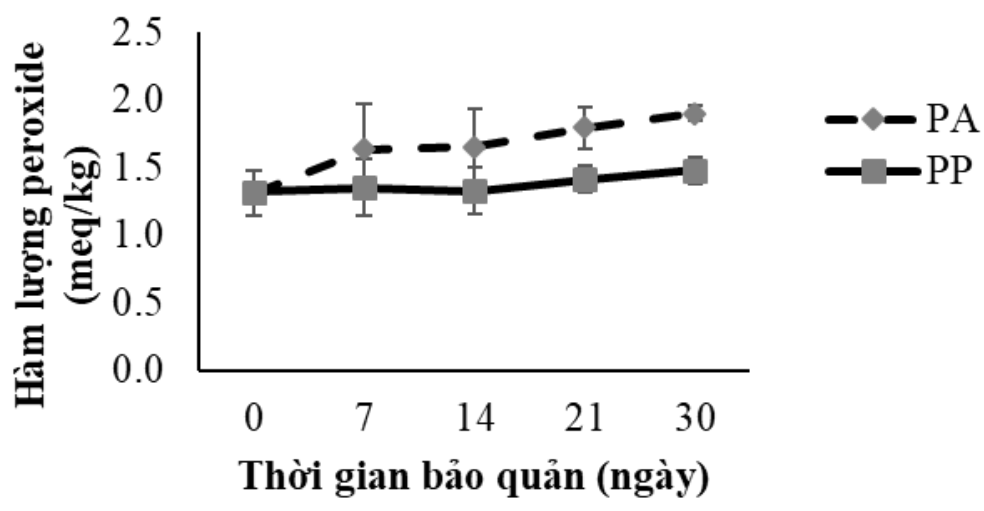

B quản mẫu bằng bao tráng nhôm giúp duy trì chất lượng lượng của mẫu tốt hơn so với bao PA.

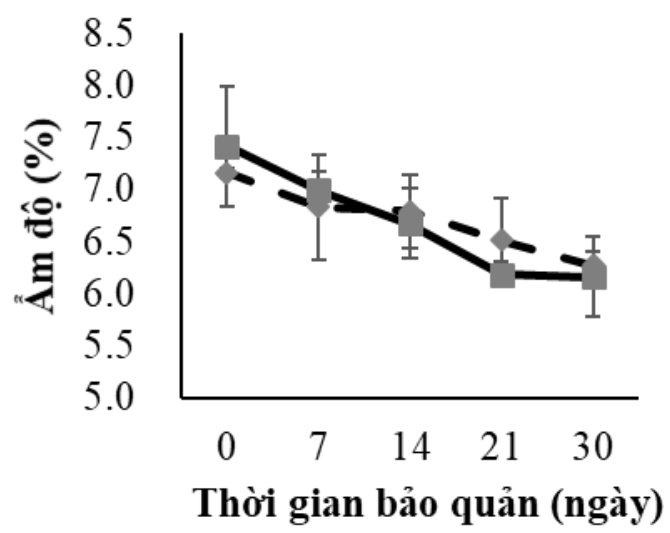

$\mathbf{C}$

Hình 4. Ảnh hưởng của loại bao bì bảo quản đến biến đổi $(\mathrm{A})$ hoạt độ nước, $(\mathrm{B})$ ẩm độ và $(\mathrm{C})$ hàm lượng peroxide của mẫu bảo quản tại nhiệt độ phòng

PA: polyamide, PP: polypropylene tráng nhôm. Giá trị trung bình vói các ký tụ $(a, b, c)$ giống nhau trong cùng một định dạng cột là khác biệt không có ý nghĩa thống kê ( $p>0.05)$.

\section{KẾT LUẬN}

Hạt chanh dây được tiền xử lý bằng phương pháp ngâm trong dung dịch $\mathrm{NaHCO} 3 \%$ trong 16 giờ đã giúp cải thiện độ giòn xốp cho hạt và có điểm cảm quan tốt nhất 5,5/7. Hàm lượng polyphenol trong hạt giảm sau mỗi công đoạn chế biến: giảm khoảng $7 \%$ sau tiền xử lý, $9 \%$ sau sấy và $18 \%$ sau rang. Kết quả đã ghi nhận thanh dinh dưỡng được chế biến từ các thành phần: hạt gạo lứt, hạt hướng dương, hạt đậu phộng, hạt đậu nành, hạt điều, hạt mè trắng với tỷ lệ hạt chanh dây trong sản phẩm là $15 \%$ được nhiều cảm quan viên yêu thích nhất về các thuộc tính kết cấu, mùi vị; đồng thời ở tỷ lệ phối trộn này có hàm lượng polyphenol tổng và hoạt tính kháng oxy hóa lần lượt là $366,50 \mathrm{mg}$ GAE/100 g và $561,64 \mathrm{mg}$ $\mathrm{AAE} / 100 \mathrm{~g}$. Thông số dinh dưỡng cơ bản của sản phẩm là: protein $17,2 \mathrm{~g}$; chất béo $25,3 \mathrm{~g}$; carbohydrate $49,2 \mathrm{~g}$ và năng lượng $493 \mathrm{kcal}$ tính trên $100 \mathrm{~g}$ sản phẩm. Trong thời gian bảo quản, sử dụng bao bì chắn sáng đã giúp hạn chế quá trình peroxide hóa hơn so với bao bì không chắn sáng, hàm lượng peroxide của sản phẩm sau 60 ngày tương ứng lần lượt là $2,08 \mathrm{meq} / \mathrm{kg} ; 2,14 \mathrm{meq} / \mathrm{kg}$ đảm bảo an toàn theo TCVN 10127:2013 (Bộ Khoa học và Công nghệ, 2013). Độ ẩm và hoạt độ nước giảm 
dần theo thời gian bảo quản ở cả bao bì chắn sáng và không chắn sáng.

\section{LÒ̀I CẢM ƠN}

Nhóm tác giả chân thành cảm ơn sự hỗ trợ kinh phí từ tổ chức VLIR-UOS - VN2018TEA478A103 (Bi).

\section{TÀI LIỆU THAM KHẢO}

Ahmad, A., Irfan, U., Amir, R. M., \& Abbasi, K. S. (2017). Development of high energy cereal

and nut granola bar. International Journal of Agriculture and Biological Sciences, 1(3), 13-20.

Bộ Khoa học và Công nghệ. (2010). Tiêu chuẩn quốc gia. -Dầu mỡ động vật và thực vật - Xác định trị số peroxit - Phương pháp xác định điểm kết thúc chuẩn độ iốt (TCVN 6121: 2010-ISO 3960: 2007)

Bộ Khoa học và Công nghệ. (2013). Tiêu chuẩn quốc gia - Dầu và mỡ thực phẩm không thuộc đối tượng của các tiêu chuẩn cụ thể (TCVN 6121: 2010-ISO 3960: 2007).

Chau, C. F., \& Huang, Y. L. (2004). Characterization of passion fruit seed fibres - A potential

fibre source. Food Chemistry, 85(2), 189-194.

Mendes, N. D. S. R., Gomes-Ruffi, C. R., Lage, M. E., Becker, F. S., Melo, A. A. M. D., Silva,

F. A. D., \& Damiani, C. (2013). Oxidative stability of cereal bars made with fruit peels and baru nuts packaged in different types of packaging. Food Science and Technology, 33(4), 730-736.

Nguyen, N. M. P., Le, T. T., Vissenaekens, H., Gonzales, G. B., Van Camp, J., Smagghe, G.,

\& Raes, K. (2019). In vitro antioxidant activity and phenolic profiles of tropical fruit byproducts. International Journal of Food Science \& Technology, 54(4), 1169-1178.

Padmashree, A., Negi, N., Haridas, S., Govindaraj, T., Kumar, K. R. A., Semwal, A. D., \&
Sharma, G. K. (2018). Development and Quality Evaluation of Choco Quinoa Nutri Bar during Storage. Food and Nutrition Sciences, 9(7), 899-914.

Palazzolo, G. (2003). Cereal bars: they're not just for breakfast anymore. Cereal Foods World, 48(2), 70.

Piombo, G., Barouh, N., Barea, B., Boulanger, R., Brat, P., Pina, M., \& Villeneuve, P. (2006).

Characterization of the seed oils from kiwi (Actinidia chinensis), passion fruit (Passiflora edulis) and guava (Psidium guajava). Oléagineux, Corps Gras, Lipides, 13(2-3), 195-199.

Ramaiya, S. D., Bujang, J. S., \& Zakaria, M. H. (2019). Physicochemical, fatty acid and

antioxidant properties of passion fruit (Passiflora species) seed oil. Pakistan Journal of Nutrition, 18(5), 421-9.

Reis, L. C. R. D., Facco, E. M. P., Salvador, M., Flôres, S. H., \& de Oliveira Rios, A. (2018).

Antioxidant potential and physicochemical characterization of yellow, purple and orange passion fruit. Journal of Food Science and Technology, 55(7), 2679-2691.

Singleton, V. L., \& Rossi, J. A. (1965). Colorimetry of total phenolics with phosphomolybdic-

phosphotungstic acid reagents. American journal of Enology and Viticulture, 16(3), 144-158.

Thaipong, K., Boonprakob, U., Crosby, K., Cisneros-Zevallos, L., \& Byrne, D. H. (2006).

Comparison of ABTS, DPPH, FRAP, and ORAC assays for estimating antioxidant activity from guava fruit extracts. Journal of Food Composition and Analysis, 19(6-7), 669-675.

Yadav, L., \& Bhatnagar, V. (2016). Formulation, quality evaluation and shelf-life of value

added cereal bar by incorporation of defatted soy flour. International Journal of Food and Fermentation Technology, 6(2), 251-259. 